\title{
Electrochemical synthesis and characterization of chloride doped polyaniline
}

\author{
A M PHARHAD HUSSAIN and A KUMAR* \\ Department of Physics, Tezpur University, Napaam, Tezpur 784 028, India \\ MS received 3 September 2002; revised 2 January 2003
}

\begin{abstract}
Chloride doped polyaniline conducting polymer films have been prepared in a protic acid medium (HCl) by potentiodynamic method in an electrochemical cell and studied by cyclic voltammetry and FTIR techniques. The FTIR spectra confirmed $\mathrm{Cl}^{-}$ion doping in the polymers. The polymerization rate was found to increase with increasing concentration of aniline monomer. But the films obtained at high monomer concentration were rough having a nonuniform flaky polyaniline distribution. Results showed that the polymerization rate did not increase beyond a critical $\mathrm{HCl}$ concentration. Cyclic voltammetry suggested that, the oxidation-reduction current increased with an increase in scan rate and that the undoped polyaniline films were not hygroscopic whereas chloride doped polyaniline films were found to be highly hygroscopic.
\end{abstract}

Keywords. Conducting polymer; electrochemical synthesis; polyaniline; cyclic voltammetry; FTIR.

\section{Introduction}

Research in electroactive polymers, particularly in aromatic conducting polymers, has received considerable attention worldwide in the past few years because of their potential applications in the fields of microelectronics, optics and optoelectronics (Bernard et al 1998, 2001; Schultze et al 1999; Mousty et al 2001). Among these polymers, polyaniline (PAni) is one of the most widely studied conducting polymers because of its good conductivity that can be influenced both by the charging level and degree of protonation, its well defined electrochemical (redox) response, easy preparation and possible applications in rechargeable batteries, corrosion protection, light emitting diodes, molecular sensors, electrochromic devices and microwave screening (Inzelt et al 2001). Polyaniline is not charge conjugation symmetric, i.e. the valence and conduction bands are asymmetric to a great extent (Ghos et al 2001). A partial oxidation of PAni usually leads to the reorganization of bonds, resulting in an increase in electronic conductivity. The physicochemical properties of PAni are strongly related to the proportion of aryl amine and quinone imine units present (Genies et al 1988). PAni possesses two voltammetric redox pairs including three stable oxidation states, with the half-oxidized state (emaraldine) being highly conductive in its protonated state. Existence of different oxidation states of PAni makes it useful as an electrode material in electrochemical capacitors (Roßberg et al 1998; Fusalba et al 2001; Hu and Chu 2000, 2001).

\footnotetext{
*Author for correspondence
}

In the present study polyaniline films have been prepared by electropolymerization from an electrolyte containing $\mathrm{HCl}$ and aniline monomer at different concentration ratios. The polymer films have been studied by cyclic voltammetry. FTIR spectra have been recorded for confirmation of $\mathrm{Cl}^{-}$ion doping of the polymer films.

\section{Experimental}

Aniline (SRL, India) was distilled under reduced pressure and stored in darkness before use. As received $\mathrm{HCl}$ (Qualigens, India) and purified double distilled water were used in preparing the electrolyte solution. An electrochemical cell consisting of working and secondary electrodes of stainless steel was used. Saturated calomel electrode (SCE) was used as reference electrode. The electrolyte consisted of an aqueous solution of aniline monomer and acid $\mathrm{HCl}$. Polymerization was carried out potentiodynamically using a potentiostate/galvanostate [Analytical Electrochemical Workstation, AEW2, Sycopel Scientific Ltd.]. Three samples were prepared from baths containing monomer concentrations of $0.05 \mathrm{M}, 0.1 \mathrm{M}$ and $0 \cdot 15 \mathrm{M}$, respectively keeping the acid concentration fixed at $1 \mathrm{M}$ and three samples were prepared with three different acid concentrations of $0.5 \mathrm{M}, 1.5 \mathrm{M}$ and $2.0 \mathrm{M}$ at constant monomer concentration of $0.1 \mathrm{M}$. The deposition was carried up to 40 cycles at a scan rate of $25 \mathrm{mV} / \mathrm{s}$. The potential was varied between $-100 \mathrm{mV}$ and $1400 \mathrm{mV}$ for deposition as well as for cyclic voltammetry experiments. Cyclic voltammograms of the polymers were recorded at scanning rates of $10,20,40$ and $50 \mathrm{mV} / \mathrm{s}$. Electrical conductivity has been measured by LCR 
Hitester Hioki model 3532-50. The FTIR spectra of the polyaniline samples have been taken by using Nicolet Impact 410 FTIR spectrophotometer.

\section{Results and discussion}

\subsection{Electrochemical deposition of polyaniline}

Depositions of the polymer films were carried out electrochemically by varying the monomer as well as acid concentrations. The deposition yielded a deep green film of polyaniline. Steps involved in the possible mechanism of the oxidative electropolymerization of aniline to polyaniline are given in figure 1. The polymerization takes place by oxidation at $1.0-1.2 \mathrm{~V}$ while potential is increasing followed by a de-protonation at $0 \cdot 6-0 \cdot 2 \mathrm{~V}$ in the reverse direction of potential. At lower monomer concentrations of $0.05 \mathrm{M}$ and $0.1 \mathrm{M}$ of aniline, the deposited films exhibit a smooth surface, uniform distribution and good adhesion to the electrode though the polymerization rate (i.e. the deposition current) is low. Figure 2 is the plot of deposition current (a measure of polymerization rate) as a function of monomer concentration. The figure shows that polymerization rate increases monotonically with monomer concentration and that at $0.15 \mathrm{M}$ aniline concentration, the polymerization rate (deposition current) is quite high, but the film obtained has a rough surface, is flaky and shows poor adhesion. This may be

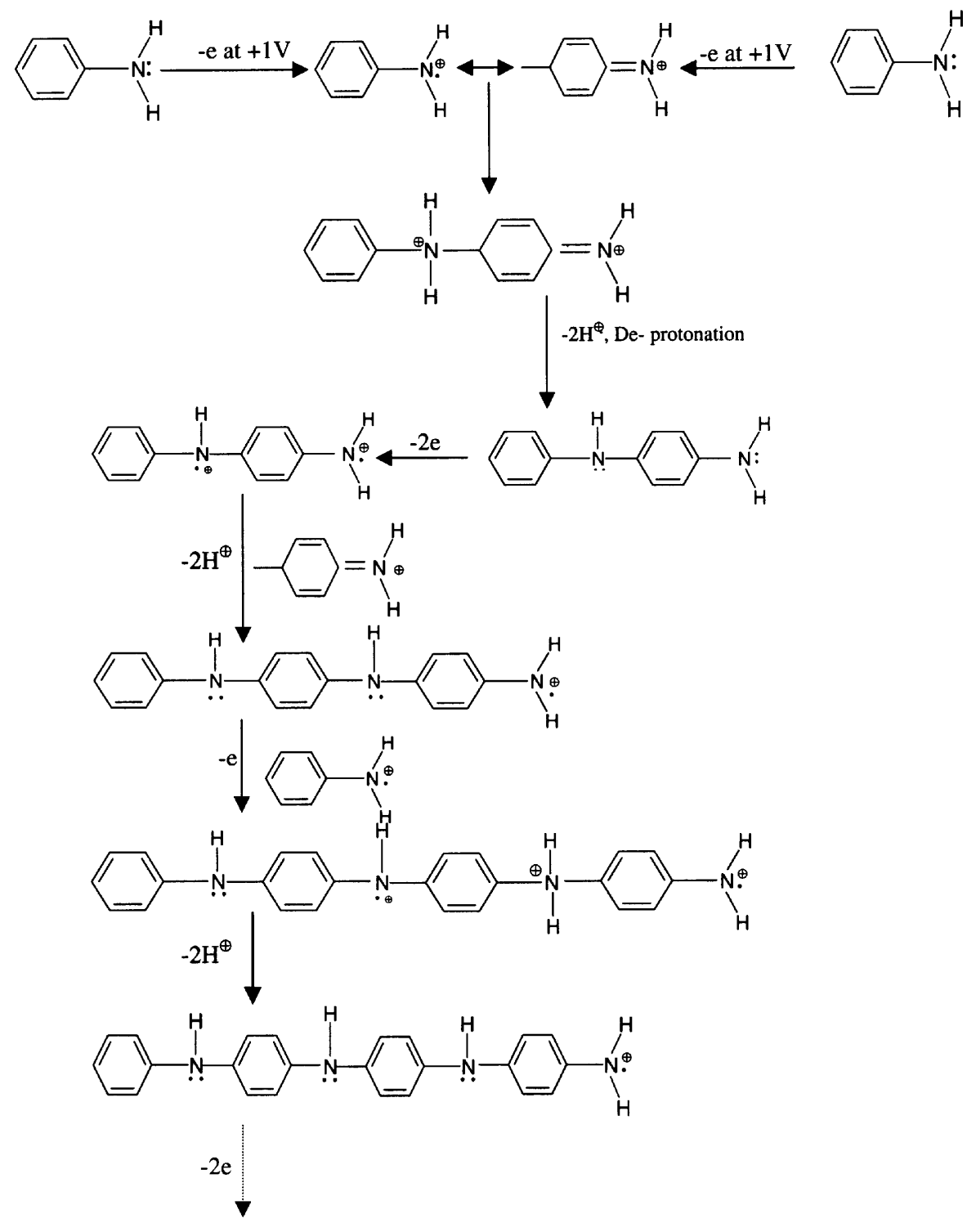

Polymer

Figure 1. Mechanism of oxidative electropolymerization of aniline. 
attributed to the faster rate of polymerization due to higher monomer concentration which does not provide time for polymer chains to stick smoothly on to the stainless steel electrodes. In table 1 are given the peak currents obtained in different cycles during polymerization at different monomer concentrations and $1.0 \mathrm{M} \mathrm{HCl}$ concentration. It is observed that the current in 5th cycle for $0.15 \mathrm{M}$ monomer concentration is almost double to the current in 10th cycle for low monomer concentrations of $0.05 \mathrm{M}$ and $0.1 \mathrm{M}$, which implies that the rate of polymerization for $0 \cdot 15 \mathrm{M}$ monomer concentration is roughly double to that for $0.05 \mathrm{M}$ and $0.1 \mathrm{M}$ monomer concentrations. These results suggest that even though the polymerization rate may be slower, but for improved adhesion and smooth and uniform films on stainless steel electrode the monomer concentration should be kept low $(0 \cdot 1 \mathrm{M})$.

The polymer films obtained by varying the acid concentration, however, do not show any notable change. The slow rate at low $\mathrm{HCl}$ concentration could be ascribed to lower proton concentration and hence lower protonation rate of the film. The rate of polymerization, however, does not increase monotonically with $\mathrm{HCl}$ concentration. Figure 3 shows that the deposition current gets saturated as $\mathrm{HCl}$ concentration exceeds $1.5 \mathrm{M}$, which implies that higher proton concentration cannot increase polymerization rate beyond a certain limit. The chloride ion $\left(\mathrm{Cl}^{-}\right)$from the electrolyte enters the polymer film in the oxidative polymerization and remains in the polymer chain as dopant and contributes to oxidation/reduction by accepting/contributing one electron, which makes the polymer conducting. It is observed that the polymer films doped with chloride ion are hygroscopic and absorb moisture from air even if exposed to air for a very short period. However, undoped PAni films are not hygroscopic, and do not absorb moisture even if exposed to humid air for a long time.

\subsection{Cyclic voltammetry}

Figures $4 \mathrm{a}-\mathrm{c}$ show cyclic voltammograms $(\mathrm{CV})$ of the polyaniline films obtained at monomer concentrations $0.05 \mathrm{M}, 0.1 \mathrm{M}$ and $0.15 \mathrm{M}$, respectively in $1.0 \mathrm{M} \mathrm{HCl}$ at different scan rates $(10,20,40$ and $50 \mathrm{mV} / \mathrm{s})$. Figures $5 \mathrm{a}-\mathrm{c}$ show similarly the cyclic voltammograms of the polyani- line films recorded in $0.5 \mathrm{M}, 1.5 \mathrm{M}$ and $2.0 \mathrm{M} \mathrm{HCl}$ electrolytes, respectively containing a constant monomer concentration of $0 \cdot 1 \mathrm{M}$. The cyclic voltammetry of polyaniline has been extensively discussed in the literature (Bernard et al 1998, 1999; Hatchett et al 1999; Rajendran et al 2000; Chen et al 2002; Schemid 2002). Voltammograms of the PAni at various scan rates can be differenti-

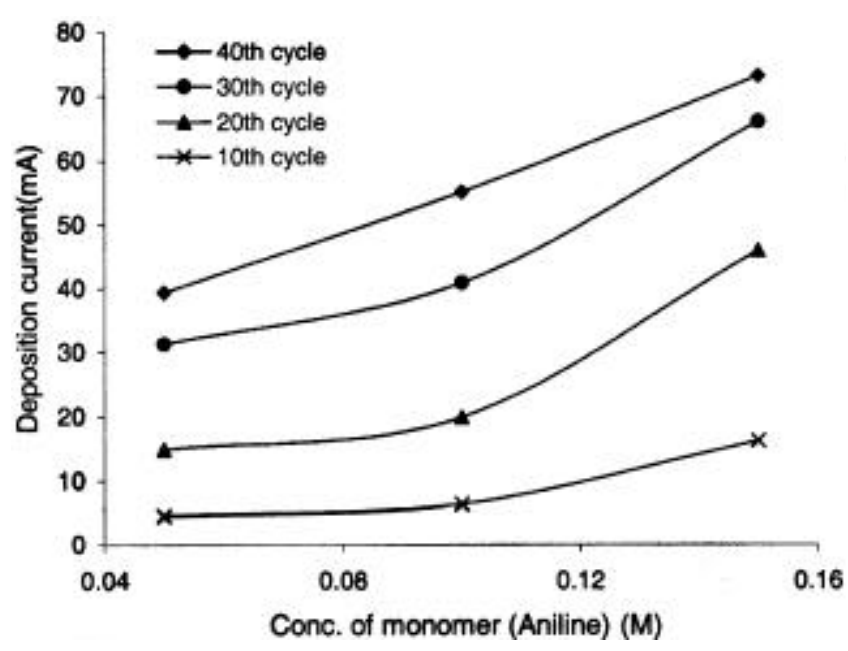

Figure 2. Monomer concentration vs deposition current showing a gradual increase in current with monomer concentration.

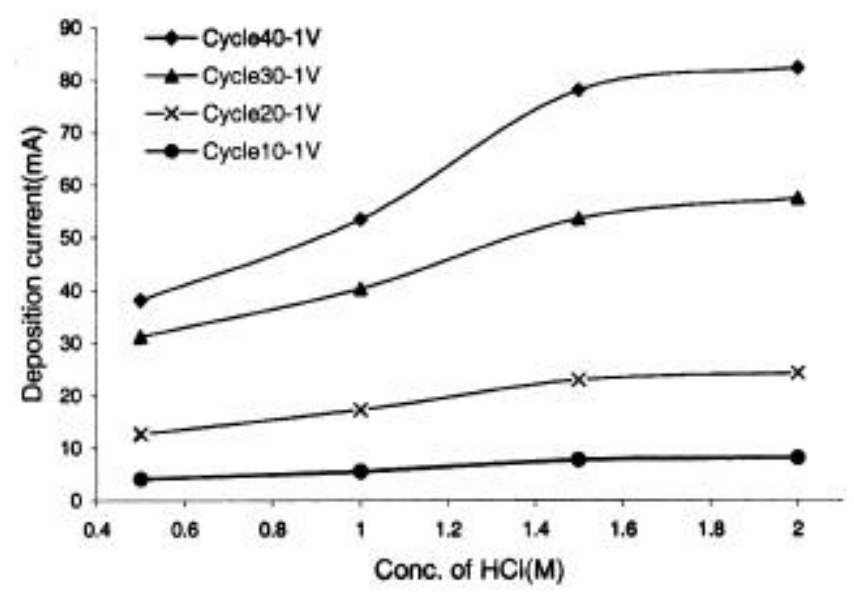

Figure 3. $\mathrm{HCl}$ concentration vs deposition current showing saturation at higher $\mathrm{HCl}$ concentration.

Table 1. Peak deposition current of different deposition cycles at constant $\mathrm{HCl}$ concentration and different monomer concentrations.

\begin{tabular}{lccccc}
\hline $\begin{array}{l}\text { Monomer } \\
\text { concentration } \\
(\mathrm{M})\end{array}$ & $\begin{array}{c}\text { Peak deposition } \\
\text { current at 5th cycle } \\
(\mathrm{mA})\end{array}$ & $\begin{array}{c}\text { Peak deposition } \\
\text { current at 10th cycle } \\
(\mathrm{mA})\end{array}$ & $\begin{array}{c}\text { Peak deposition } \\
\text { current at 20th cycle } \\
(\mathrm{mA})\end{array}$ & $\begin{array}{c}\text { Peak deposition } \\
\text { current at 30th cycle } \\
(\mathrm{mA})\end{array}$ & $\begin{array}{c}\text { Peak deposition } \\
\text { current at 40th cycle } \\
(\mathrm{mA})\end{array}$ \\
\hline 0.05 & $5 \cdot 878$ & 8.529 & 20.984 & 31.547 & $40 \cdot 889$ \\
0.10 & 6.142 & $8 \cdot 749$ & 24.081 & 41.596 & $58 \cdot 794$ \\
0.15 & 16.97 & 29.961 & $50 \cdot 348$ & 68.433 & 88.381 \\
\hline
\end{tabular}


ated into three main regions. (i) $0.0 \mathrm{~V}$ to $+0.6 \mathrm{~V}$ is completely reduced state, (ii) from about $0.6 \mathrm{~V}$ to $0.9 \mathrm{~V}$ the PAni is in partially oxidized state and (iii) from about $0.9 \mathrm{~V}$ to $1.4 \mathrm{~V}$ it is in completely oxidized state. In figure $4 \mathrm{c}$ the reduction and de-protonation peaks are distinctly visible. In figure $4 \mathrm{~b}$ the de-protonation peak is present
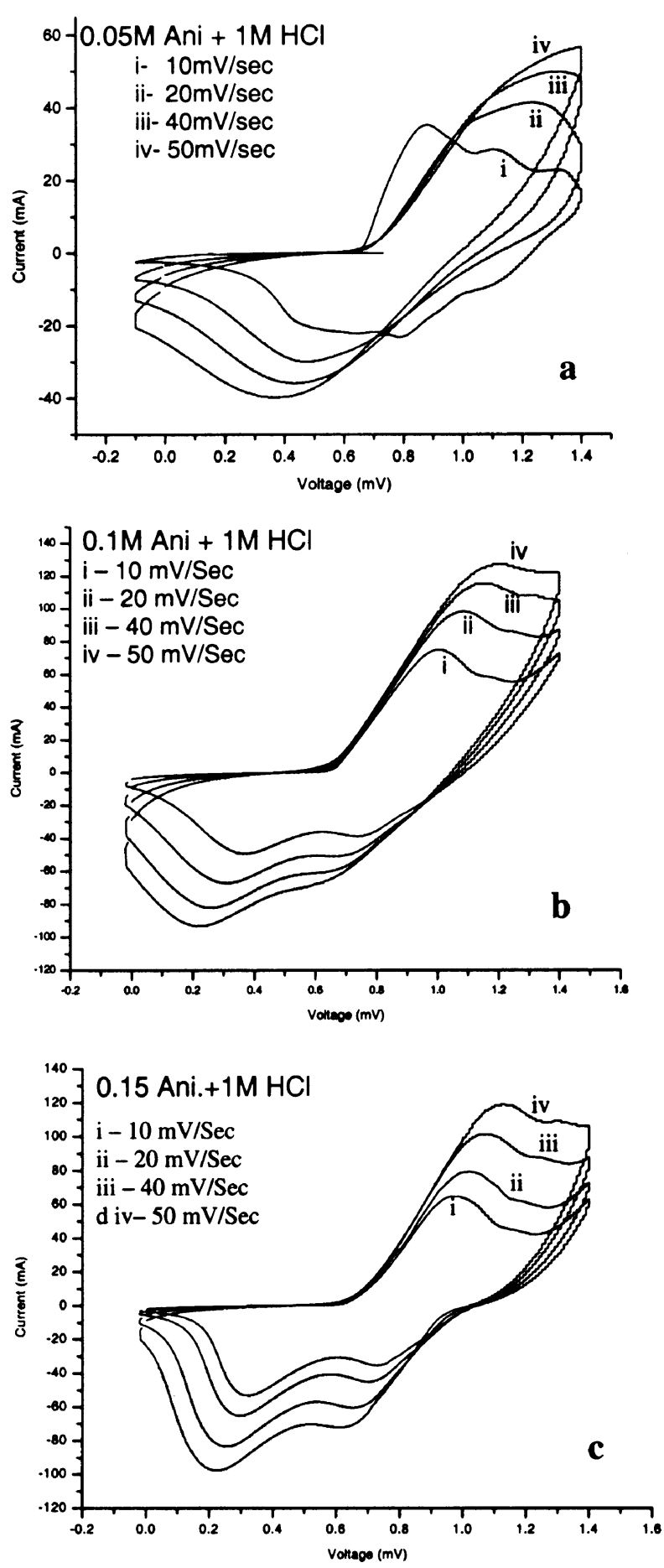

Figure 4. Cyclic voltammogram at different scan rates for (a) $0.05 \mathrm{M},(\mathbf{b}) 0.1 \mathrm{M}$ and (c) $0.15 \mathrm{M}$ aniline in $1.0 \mathrm{M} \mathrm{HCl}$. but it is smaller than the reduction peak. In figure $4 \mathrm{a}$, de-protonation peak is completely absent. The reduction peak for scan rate of $10 \mathrm{mV} / \mathrm{s}$ occurred at comparatively higher potential. In figures $5 \mathrm{a}-\mathrm{c}$ also we can see separate reduction and deprotonation peaks at low scan rate $(10 \mathrm{mV} / \mathrm{s})$, but the peaks get diffused into a single peak at
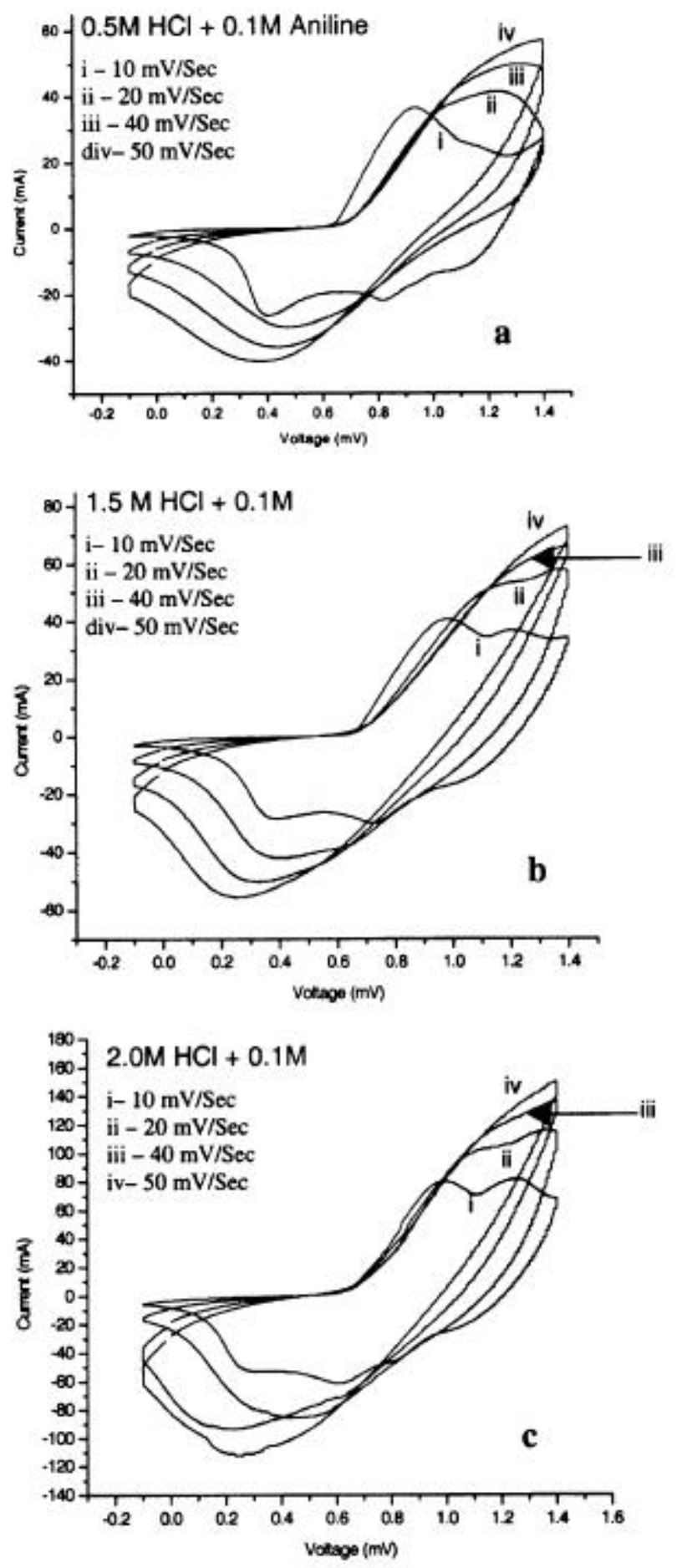

Figure 5. Cyclic voltammogram at different scan rates for $0.1 \mathrm{M}$ aniline in (a) $0.5 \mathrm{M}$, (b) $1.5 \mathrm{M}$ and (c) $2.0 \mathrm{M} \mathrm{HCl}$. 


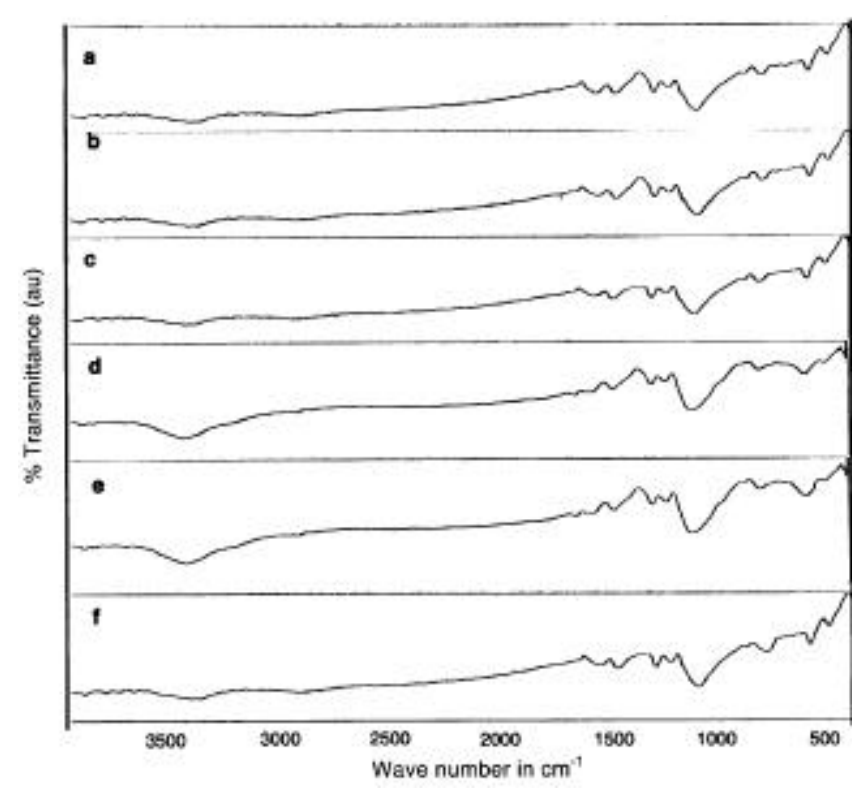

Figure 6. FTIR spectra of the polymer films (a) $0.05 \mathrm{M}$ aniline, (b) $1.0 \mathrm{M}$ aniline and (c) $1.5 \mathrm{M}$ aniline in $1 \mathrm{M} \mathrm{HCl}$ and (d) $0.5 \mathrm{M}$, (e) $1.5 \mathrm{M}$ and (f) $2.0 \mathrm{M} \mathrm{HCl}$ with $0.1 \mathrm{M}$ aniline.

higher scan rates. From the cyclic voltammetry study we can say that both the cathodic and anodic currents are higher at higher acid concentration. This may be due to the increase in proton concentration in the electrolyte, which favours rapid protonation-deprotonation giving rise to larger currents. The colour of the PAni films changes from light green (bottle green) to deep green, which is also an indication of the oxidation-reduction taking place in the polymer electrode. The current density also increases/decreases in oxidation/reduction processes, more rapidly with the increase in scan rate. The oxidation peak for all the six films occurred in the region $1 \cdot 0-1 \cdot 2 \mathrm{~V}$. Films of higher monomer concentration showed a little low oxidation peak near $1 \mathrm{~V}$. The reduction and de-protonation peaks were found to lie in the range of $0 \cdot 2-0 \cdot 8 \mathrm{~V}$. Interestingly no separate protonation peaks are observed in all the six samples. A broad peak, instead of two sharp peaks, one of protonation and the other of oxidation, is observed in our experiments. From these observations we conclude that the protonation and the oxidation are occurring at two very close potentials.

\subsection{Conductivity and FTIR spectroscopy}

The conductivity of the chloride doped and undoped polyaniline films are measured at room temperature $\left(27^{\circ} \mathrm{C}\right)$ using LCR meter by two-probe method. The conductivity of the undoped films are of the order of $10^{-10} \mathrm{~S} / \mathrm{cm}$, whereas those of chloride doped films are of the order of $18-24 \mathrm{~S} / \mathrm{cm}$.

The FTIR spectra of polymer films obtained at constant $\mathrm{HCl}$ concentration of $1.0 \mathrm{M}$ with changing mono- mer concentrations of $0.05 \mathrm{M}, 0.1 \mathrm{M}$ and $0.15 \mathrm{M}$ are presented in figures $6 \mathrm{a}-\mathrm{c}$, respectively. Figures $6 \mathrm{~d}-\mathrm{f}$ show the FTIR spectra of polymers of constant monomer concentration, $0 \cdot 1 \mathrm{M}$, with changing $\mathrm{HCl}$ concentrations, $0.5 \mathrm{M}, 1.5 \mathrm{M}$ and $2.0 \mathrm{M}$, respectively. The peak near $800 \mathrm{~cm}^{-1}$ is due to the $\mathrm{N}-\mathrm{H}$ out-of-plane bending absorption. The strongest band observed near $1100 \mathrm{~cm}^{-1}$ and the band at $1235 \mathrm{~cm}^{-1}$ are due to $\mathrm{C}-\mathrm{C}$ stretching and $\mathrm{C}-\mathrm{C}$ twisting, respectively of the alkyl chain (Schemid et al 2002). The peak at $1300 \mathrm{~cm}^{-1}$ is due to the $\mathrm{C}-\mathrm{N}$ stretching of the polymer. The $\mathrm{C}=\mathrm{C}$ stretch absorption of aromatic compound generally occurs in the range of 1475$1600 \mathrm{~cm}^{-1}$, in this study this peak was obtained at $1477 \mathrm{~cm}^{-1}$. The peak due to $\mathrm{N}-\mathrm{H}$ bending can be seen in the range of $1560-1640 \mathrm{~cm}^{-1}$. The peak near $3000 \mathrm{~cm}^{-1}$ is due to the $\mathrm{C}-\mathrm{H}$ stretching absorption. The stretching peak of $\mathrm{N}-\mathrm{H}$ appeared in the range of $3420-3450 \mathrm{~cm}^{-1}$. The $\mathrm{C}-\mathrm{Cl}$ stretching peak arises in the range of $590-700 \mathrm{~cm}^{-1}$ (Koenig 1999; Pavia et al 2001). This confirmed the $\mathrm{Cl}^{-}$ doping of the electrochemically synthesized polyaniline films in $\mathrm{HCl}$.

\section{Conclusion}

In the present work chloride doped polyaniline films have been directly prepared from an electrolyte containing $\mathrm{HCl}$. The results show that for quality polyaniline films of smooth surface, better adhesion, less porosity and uniform distribution, the monomer concentration should be kept low $(\approx 0 \cdot 1 \mathrm{M})$, though the rate of polymerization is low at this concentration. At higher concentration, $(0.15 \mathrm{M})$ of aniline, the rate of polymerization is high, but the film surface is rough, nonuniform, flaky and show poor adhesion to the electrode. It can also be concluded that the higher acid concentration does not lead to increase in the rate of polymerization beyond a certain limit. Cyclic voltammetry results show that oxidation of the polymer films occurs in the potential range of $1-1.2 \mathrm{~V}$ and the reduction occurs in the range of $0 \cdot 2-$ $0.8 \mathrm{~V}$. FTIR spectra confirm the $\mathrm{Cl}^{-}$ion doping in the polymer films.

\section{Acknowledgements}

We gratefully acknowledge UGC, New Delhi, for financial assistance (vide project no. F.10-53/2001 (SR-I). Help extended by Mr B Gohain, Department of Chemical Sciences, Tezpur University, in taking the FTIR spectra is also acknowledged.

\section{References}

Bernard M C, Goff A H L and Zeng W 1998 Electrochimica Acta $\mathbf{4 4} 781$ 
Bernard M C, Torresi S C and Goff A H L 1999 Electrochimica Acta 441989

Bernard M C, Joiret S, Goff A H and Long P D 2001 J. Electrochem. Soc. 148 B299

Champagne S D, Ferain E, Jerome C, Jerome R and Legras R 1998 Electrochimica Acta 1767

Chen W, Wen T, Hu C and Gopalan A 2002 Electrochimica Acta 471305

Fusalba F, Gouerec P, Villers D and Belanger D $2001 \mathrm{~J}$. Electrochem. Soc. 148 A1

Genies E M, Lapkowski M and Tsintavis C 1988 J. Chem. 12 181

Ghos M, Meikap A K, Chattopadhyay S K and Chatterjee S 2001 J. Phys. \& Chem. Solids 62475

Hatchett D W, Josowicz M and Janata J 1999 J. Electrochem. Soc. 1464535

Heeger A J 2001 Curr. Appl. Phys. 1247

Hu C C and Chu C H 2000 Mater. Chem. Phys. 65329
Hu C C and Chu C H 2001 J. Electroanal. Chem. 503105

Inzelt G, Csahók E and Kertész V 2001 Electrochimica Acta 46 3955

Koenig J L 1999 Spectroscopy of polymers (Amsterdam: Elsevier) 2nd ed

Mousty C, Lepellec A, Cosnier S, Novoa A and Marks R S 2001 Electrochem. Commun. 3727

Pavia D L, Lampman G M and Kriz G S 2001 Introduction to spectroscopy (Fort Worth: Harcourt College Publishers) 3rd ed.

Rajendran V, Gopalan A, Vasudevan T and Wen T $2000 \mathrm{~J}$. Electr. Soc. 1473014

Roßberg K, Paasch G, Dunsch L and Ludwig S 1998 J. Electroanal. Chem. 44349

Schemid A L, Lira L M and Torresi S I C 2002 Electrochimica Acta 472005

Schultze J W, Morgenstern T, Schattka D and Winkels S 1999 Electrochimica Acta 441847 